\title{
Optimization of Efficient Route and Profitable Fish Aggregating Device Based on Firefly and Genetic Algorithms in Maritime
}

\author{
Qurrotul Aini ${ }^{1,2}$, Achmad Affandi ${ }^{1}$, Eko Setijadi ${ }^{1}$, Takuya Terasawa ${ }^{3}$, \\ and Mauridhi Hery Purnomo ${ }^{4}$ \\ ${ }^{1}$ Department of Electrical Engineering, Institut Teknologi Sepuluh Nopember, \\ Surabaya 60111, Indonesia \\ ${ }^{2}$ Department of Information Systems, Syarif Hidayatullah State Islamic University, \\ Jakarta 15412, Indonesia \\ ${ }^{3}$ School of Media Science, Tokyo University of Technology, Tokyo 1920982, Japan \\ ${ }^{4}$ Department of Computer Engineering, Institut Teknologi Sepuluh Nopember, \\ Surabaya 60111, Indonesia \\ qurrotul.aini13@mhs.ee.its.ac.id
}

\begin{abstract}
Selecting an efficient route and profitable fish aggregating device (FAD) position has become a significant matter for fishermen due to fuel limitations and environmental conditions. Certain efforts have been offered to determine the best FAD route by means of optimization methods. The firefly algorithm (FA) is one optimization method that has recently been developed and implemented. Furthermore, the genetic algorithm (GA) has been applied in many cases, including maritime. The objective of this study is to analyze the route optimization and to determine a profitable FAP based on FA and GA approaches. Simulations involving gamma value as the attractiveness variation and alpha as the randomness movements of fishing vessels are conducted. Their time complexity is computed to evaluate both performances. The mean absolute percentage error (MAPE) is also calculated in order to obtain the accuracy of forecasting/predicting the route to FAD position.
\end{abstract}

Keywords: firefly algorithm, genetic algorithm, optimization, maritime, fishing vessel.

\section{Introduction}

Maritime technology has expanded increasingly in the form of various navigation devices including the implementation of metaheuristic approach. Certain methods have been adapted from the collective behavior and interaction of living creatures following simple rules. Such approaches are promising because they can solve the problem quickly but they do not guarantee optimal problem-solving; for example, the gossip algorithm, combining with the searching algorithm breadth first search [1]. Other metaheuristic techniques have been adopted, such as the genetic algorithm (GA), ant colony optimization (ACO), the firefly algorithm (FA), and cuckoo search. Due to their flexibility in terms of problem solving, these approaches are suitable for maritime implementation.

FA is an optimization method that imitates firefly interaction behavior within its group, and is currently applied in various fields, such as power system, i.e. determining optimal power flow (OPF) with control variables and FACTS device concern [2-4] offering solution to handle redundancy optimization problem (ROP). For applications in wireless networks, a hybrid technique has been proposed to minimize cluster head energy, based on the firefly and artificial bee colony $(\mathrm{ABC})$ algorithms [5]. In healthcare, a heart disease diagnosis system utilized the chaos firefly and genetic hybrid algorithms for the learning process to search for optimal reduction of computational and gain performance [6]. A hybrid approach between FA and GA has also been applied to detect and diagnose breast cancer. FA has shown superior performance in terms of optimizing weights and biases, and has a lower mean square error than those of biogeography-based optimization, particle swarm optimization, and ACO [7]. Application FA has been investigated in queuing systems to solve multi-objective problems and parameters, such as absorption coefficient, firefly population, and number of iterations. Simulation results 
have revealed that FA is a simple, easy-to-implement method, and powerful technique [8]. Despite the FA having been widely applied for problem solving and optimization, the standard FA has the disadvantage that it may become stuck in several local optima when dealing with complex problems. Consequently, to avoid various local optima and speed up convergence, many researchers have offered a modification of FA $[9,10]$.

Various maritime studies have been conducted, particularly investigations of fishing vessels (ships), such as analyzing fishing vessel tracks and activities regarding the use of an artificial neural network to improve fishery management, and identifying a landing profile for a vessel monitoring system (VMS) [11]. Furthermore, the improvement of fishing vessel routing protocols with the gossip approach, in the existing ad hoc on-demand distance vector (AODV), has been evaluated [12]. Other supporting research has revealed the stochastic model for the fishery industry, concerning both sides (upstream and downstream) to address potential economic issues with supporting technology and applications. The integral stochastic model for fish processing value chain. This proposed model had a feature chance when dealing with realworld complications [13]. In addition, GeMASS offered a knowledge discovery system to identify abnormal maritime security threats in real time, based on GA [14]. Investigation of fishing operations has been conducted, such as purse seine optimization relied on the trip length and the cost of supplies for fishing operations [15].

In this paper, two optimization methods (FA and GA) already been applied to various problems were evaluated. GA was selected because it was suitable for handling discrete problems, in which the optimum solution was determined from a finite number of possible solutions [16]. GA exhibited reliable problem solving in many applications, and could improve the significant parameter for forecasting tools, face recognition, and simulation of some diseases [17-19]. Meanwhile, FA was selected because it was concerned with the movement of each firefly in accordance with the conditions of fishing vessels moving toward fishing locations, as an attraction with a brighter light intensity than others. Both methods were investigated dealing with maritime conditions, where the scenario was that many fishing boats scattered in the sea, attempting to reach a given FAD position [20]. The fishing vessel had to consider fuel affecting the distance and time toward the destination as well as the profitable FAD as a result of weather conditions and sea waves (figure 1). The remainder of this paper is as follows. Section 2 introducing the FA and its modification for this study, section 3 discussing the GA, section 4 explaining the simulation and results, section 5 discussing the evaluation, and section 6 presenting our conclusion.

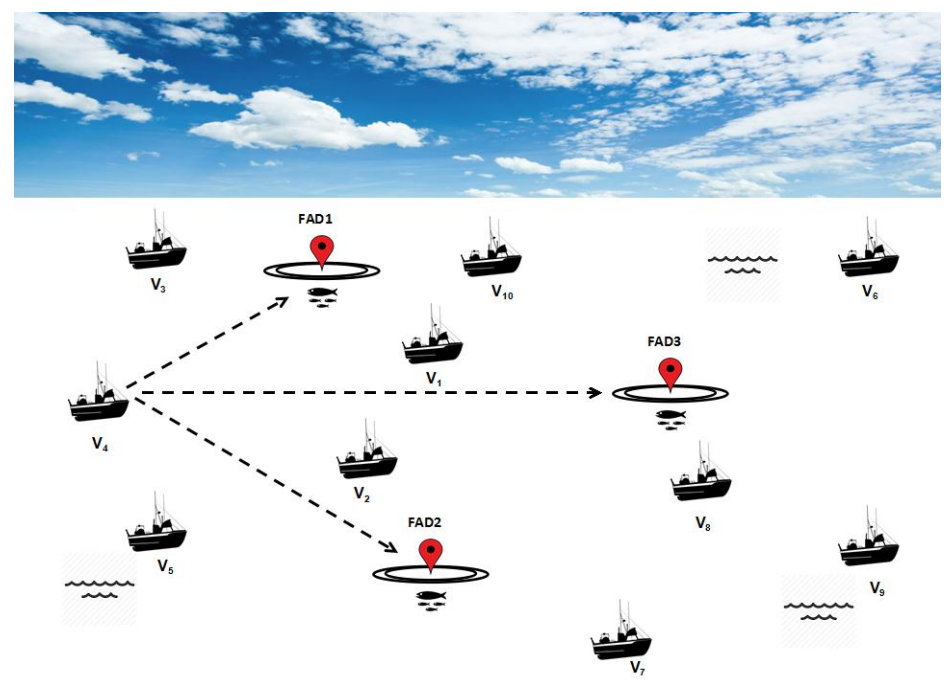

Figure 1. Fishing vessels toward FAD position 


\section{Firefly Algorithm}

In this section, the modified FA applied to the maritime problem was described. The objective functions and optimization variables used in the study were also identified, in which FA simulations involving two types of parameters namely $\gamma$ and $\alpha$ were conducted.

\section{A. Firefly Algorithm}

FA is a metaheuristic technique and a subset of swarm intelligence (SI) concerning with a group of multiple agents' behavior and the interaction among them is in accordance with certain rules. The rules describing the behavior of artificial fireflies are as follows [21]:

- All fireflies are unisex; therefore, one firefly is attracted to others.

- Attractiveness is proportional to brightness; it decreases as the distance between two fireflies increases. If there is no brighter firefly, it will move randomly.

- The brightness of a firefly is determined by the landscape of the objective function.

The objective function of the proposed method consists of the efficient path and profitable FAD position for each fishing vessel, where profitable is defined as an effective environmental condition for catching fish. The objective function used in this study is:

minimize $Z=w_{1} X_{1}+w_{2} X_{2}+w_{3} X_{3}$,

where $X_{1}=$ distance between fishing vessel and FAD;

$w_{1}=$ weight of variable $X_{1}$;

$X_{2}=$ weather condition at FAD;

$w_{2}=$ weight of variable $X_{2}$;

$X_{3}=$ sea wave condition at FAD; and

$w_{3}=$ weight of variable $X_{3}$;

Various variables of $w_{i}$ express the relative importance weight of each $X_{i}$. The exact value of $w_{i}$ can be determined based on some consideration to a particular FAD problem. In this case, it is determined by $w_{1}=0.4, w_{2}=0.2$, and $w_{3}=0.4$.

The light intensity is inversely proportional to the distance $r$ from the light source, and the light and attractiveness decrease as the distance increases.

$$
I(r)=I_{0} e^{-\gamma r^{2}},
$$

where $I$ denotes light intensity, we assume $I_{0}=1$ initially, $\gamma$ is the attractiveness coefficient, and $r$ is the distance among fireflies. The movement of a firefly $i$ is attracted to a brighter firefly $j$ defined as:

$$
x_{i}=x_{i}+\beta_{0} e^{-r_{i j}^{2}}\left(x_{j}-x_{i}\right)+\alpha(\text { rand }-0.5),
$$

where $x_{i}$ represents the position of firefly $i$, and the second part defines the attractiveness of a firefly, where $\beta_{0}$ denotes the attractiveness coefficient. In this study, firefly $j$ is considered as the FAD position. The larger the value of $\beta$, the faster the firefly will be in approaching another, brighter firefly; therefore, the searching process is faster but less accurate. Referring to equation 3 , it is set $\beta_{0}=1$, which indicates the highest attractiveness coefficient that affects the approaching of another firefly faster [22]. Furthermore, $\gamma$ represents the variation of attractiveness, including the distance to the FAD position, weather and sea wave. These variations are denoted by $\gamma_{1}, \gamma_{2}$, and $\gamma_{3}$, respectively. Likewise, $\alpha$ represents the randomness of a firefly also influenced by weather, because the movement of fishing vessels tends to be 
more random when visibility is limited by foggy conditions. table 1 shows the complete set of values for $\gamma$ and $\alpha$.

Table 1. Values of $\gamma$ and $\alpha$

\begin{tabular}{|c|c|c|}
\hline Variation of $\gamma$ & Description & Value \\
\hline$\gamma_{1}$ & Distance to FAD position & {$[0,1]$} \\
\hline$\gamma_{2}$ & Weather & $\begin{array}{l}\text { Range }[0,1] \\
\text { Foggy } \rightarrow 1 \\
\text { Cloudy } \rightarrow 0.5 \\
\text { Sunny } \rightarrow 0.01\end{array}$ \\
\hline$\gamma_{3}$ & Sea wave (m) & $\begin{array}{l}\text { Range }[0,1] \\
2.5-4.0 \rightarrow 1 \\
1.25-2.5 \rightarrow 0.5 \\
0.5-1.25 \rightarrow 0.01\end{array}$ \\
\hline$\alpha$ & Weather & $\begin{array}{l}\text { Range }[0,1] \\
\text { Foggy } \rightarrow 1 \\
\text { Cloudy } \rightarrow 0.5 \\
\text { Sunny } \rightarrow 0.01\end{array}$ \\
\hline
\end{tabular}

\section{B. Modified Firefly Optimization}

The modified firefly optimization consists of three model parts: input, process, and expected output. The input deals with the number of fishing vessels and their positions, the FAD position, and environmental status. The process applies the FA by determining certain parameters, and the output obtains the objective of this method (see figure 2).

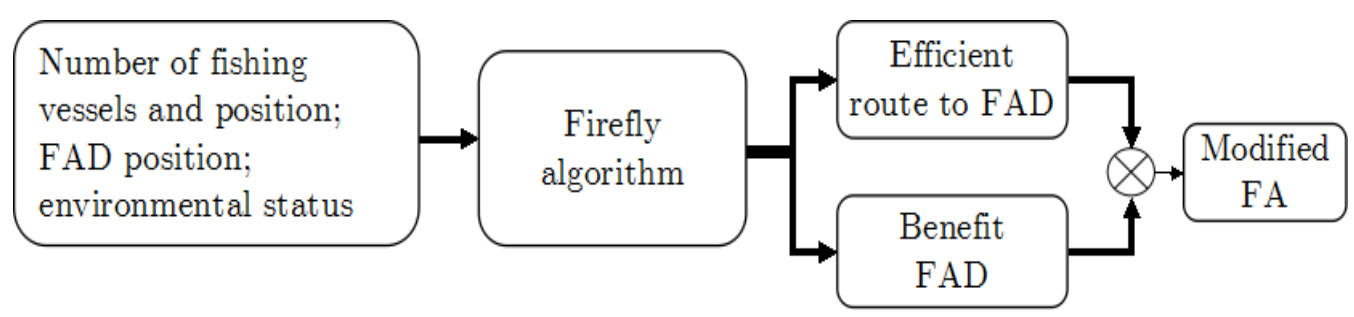

Figure 2. System Model

The optimization flowchart is shown in figure 3. It begins with certain input parameters, and then defines values for each FAD position considering the environmental sea condition. Thereafter, the value of randomness, set as $\alpha$, is defined, and $\gamma$ and the new FAD position are calculated. In addition, the movement $(p)$, based on equation 3 , is defined. 


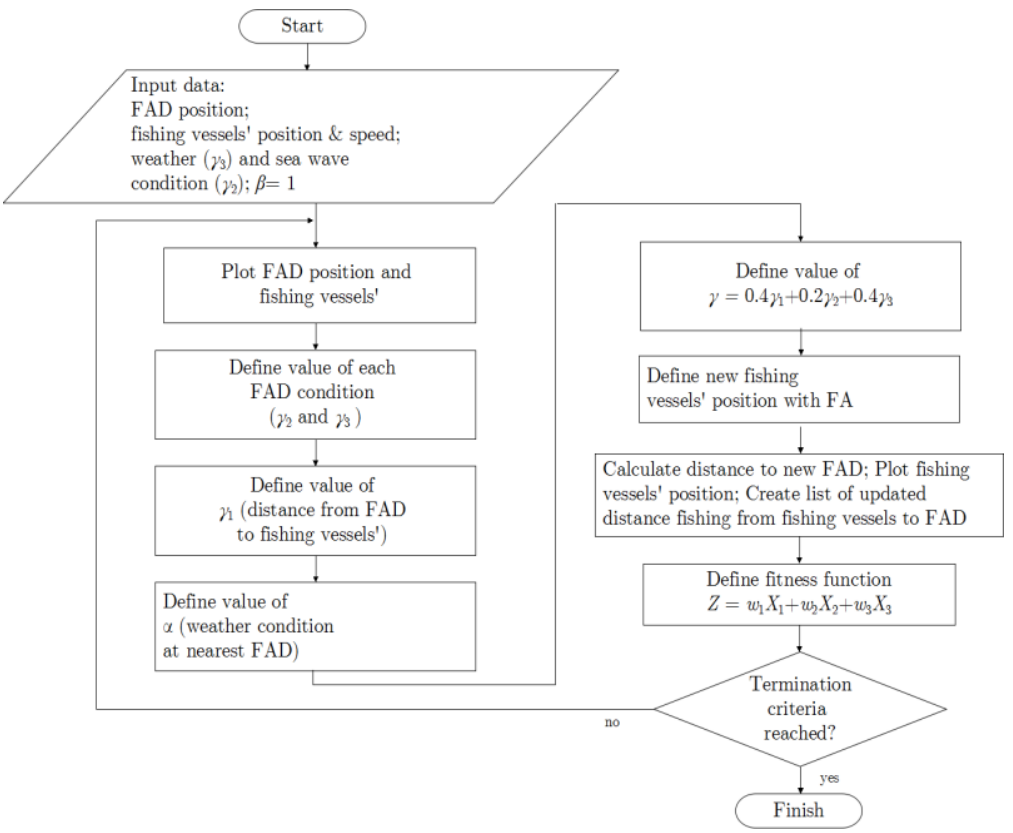

Figure 3. Modified FA Flowchart

\section{Genetic Algorithm}

GA is a population-based optimization technique classified by nature-inspired sources such as selection, crossover, and mutation [22]. This algorithm consists of the following steps. Firstly, the initial population is generated arbitrarily, and the size is adapted to the problem. Secondly, selection proceeds within the population, based on the defined fitness function. The selected individuals are parents and contribute to the next population of the generation. In this study, the fitness function is defined as an efficient route that is profitable toward the FAD position for each fishing vessel. Two operators are involved in the GA, namely crossover and mutation.

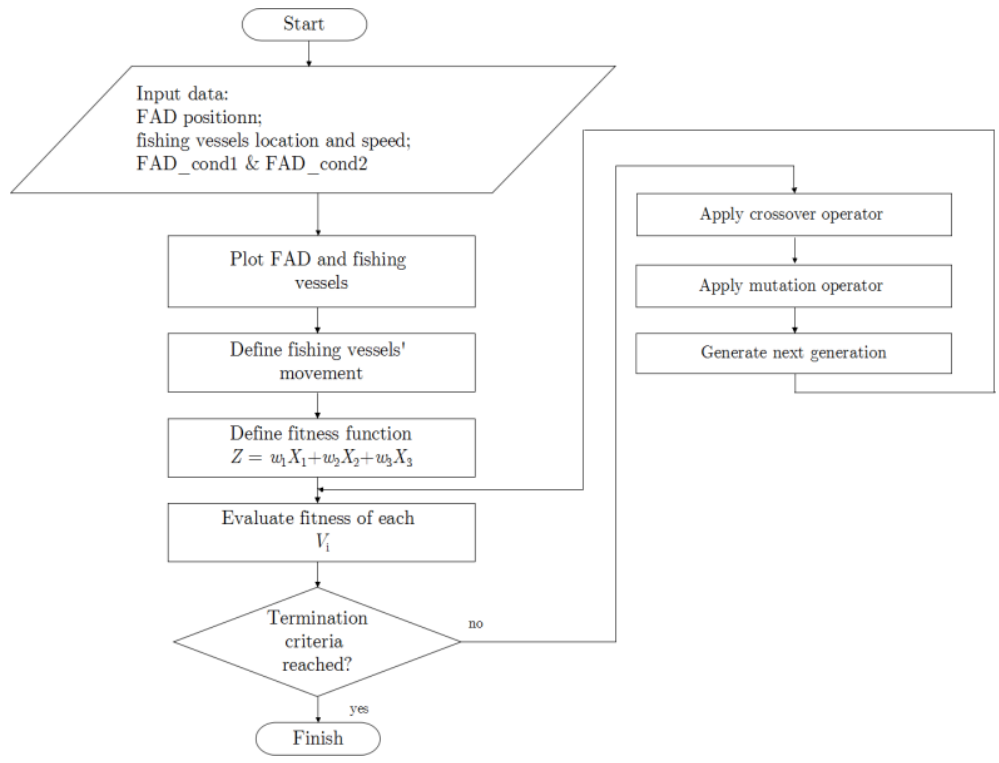

Figure 4. Modified GA Flowchart 
The function of the crossover operator involves, combining two parents to produce a new generation that has the same typical features and is superior to its parents [23]. The mutation operator, however, creates new children by implementing random changes to the individual parents. The new population of the generation terminates when a certain criterion is reached. The fitness function of the modified GA is the same as the formula in equation 3. Considering the distance from the vessels to the FAD position, this parameter could not be randomly generated. The distance toward the FAD position is a fixed parameter, and significant for this study.

\section{Simulation and Results}

\section{A. Simulation parameters and scenario}

The FA simulations were conducted in MATLAB 7.10. The scenario for this simulation was that many fishing vessels departing from the port to the FAD (figure 5). Assuming the fishing vessel is denoted as a node, while the FAD and port positions are fixed, then calculate the distance from all fishing vessels to the FAD. When they move to any FAD, the environmental conditions must be considered. The complete set of simulation parameters is shown in table 2. The simulation scenario involves 10 fishing vessels with known positions, moving toward three FAD, where each FAD has different conditions due to the environmental influences. The FAD conditions are expressed as 24 circumstances of weather $\left(\gamma_{3}\right)$ and sea waves $\left(\gamma_{2}\right)$ [24], meaning that all fishing vessels should reach their destination within 12 hours of prediction, and for the next 12 hours, they will consider coming home and time for catching fish. Under these circumstances, we implement FAD position_cond1 as $\gamma_{3}$ and FAD position_cond2 as $\gamma_{2}$. Similar to FA, at the start of the GA, input parameters and the initial population are defined.

Table 2. Simulation Parameters

\begin{tabular}{|ll|}
\hline \hline Parameter and set-up & Values \\
\hline Number of fishing vessels & 10 \\
\hline Number of FAP & 3 \\
\hline Environment size (EnvSize) & $1000 \mathrm{~km}^{2}$ \\
\hline Fishing vessel speed & $40 \mathrm{~km} / \mathrm{hour}$ \\
\hline
\end{tabular}

\section{B. Simulation}

For this simulation, 10 nodes are generated as a representation of the fishing vessels, and three FAD set-up positions i.e. FAD1, FAD2, and FAD3 (figure 5). Furthermore, the condition of each FAD is determined for 12 hours, at envSize 1000 (square kilometers) and has the same density (tons of fish per area). The initial positions of the nodes and FADs are illustrated in Fig. 4. Each fishing vessel $\left(V_{1}, \ldots, V_{10}\right)$ determines the most efficient path based on the distance and time to FAD. The positions of fishing vessels and FADs are determined in the beginning. Due to randomness, the coefficient $\alpha$ is influenced by conditions at the FAD. When conditions are clear (sunny), the fishing vessels will move straight to the FAD. Multiple simulations were conducted to obtain the FA results. The use of the rand function in Matlab affects the fishing vessels' movement during the simulation; thus, the movement always changes during any simulation, even when starting in the same initial position. The movements of each fishing vessels are illustrated in figure 5, and the results are shown in table 3 and 4. 


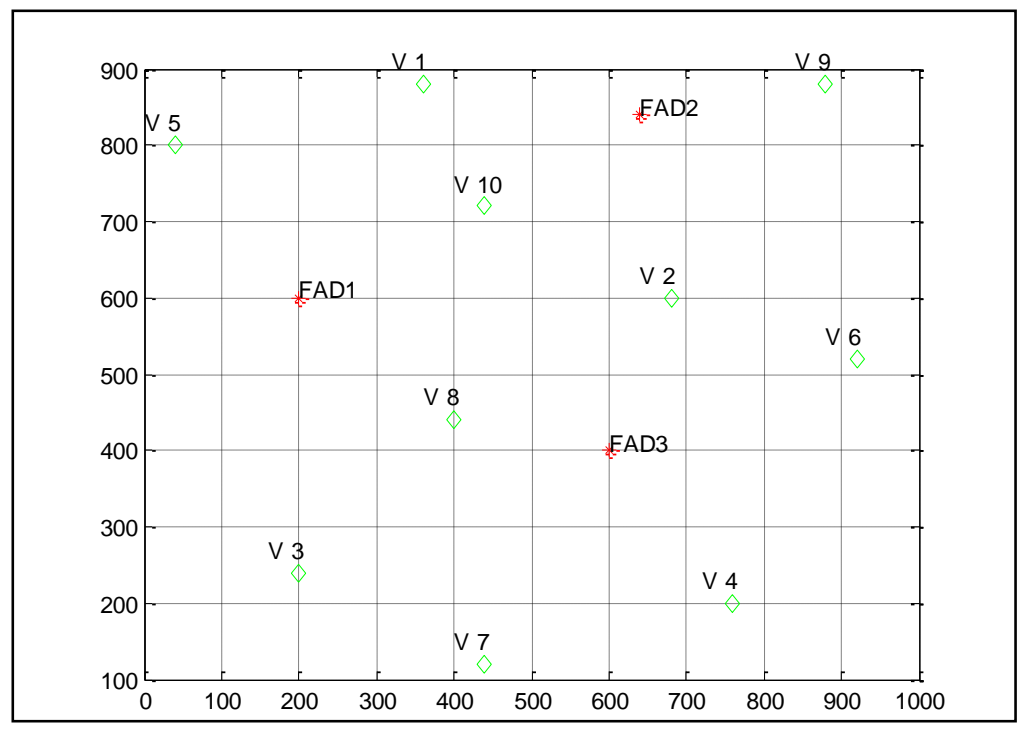

Figure 5. Initial Positions of Fishing Vessels and FAD

Table 3. Step 6 of FA Simulation

\begin{tabular}{|c|c|c|c|c|c|c|c|c|c|}
\hline \hline \multirow{2}{*}{ Vessel } & \multicolumn{3}{|c|}{ First Simulation } & \multicolumn{3}{c|}{ Second Simulation } & \multicolumn{2}{c}{ Third Simulation } \\
\cline { 2 - 9 } & $\begin{array}{c}\text { FAD } \\
\text { destination }\end{array}$ & $\begin{array}{c}\text { FAD } \\
\text { position } \\
\text { distance } \\
(\mathrm{km})\end{array}$ & $\begin{array}{c}\text { FAD } \\
\text { position } \\
\text { prediction } \\
(\mathrm{km})\end{array}$ & $\begin{array}{c}\text { FAD } \\
\text { destination }\end{array}$ & $\begin{array}{c}\text { FAD } \\
\text { position } \\
\text { distance } \\
(\mathrm{km})\end{array}$ & $\begin{array}{c}\text { FAD } \\
\text { position } \\
\text { prediction } \\
(\mathrm{km})\end{array}$ & $\begin{array}{c}\text { FAD } \\
\text { FAD } \\
\text { destination } \\
\text { position } \\
\text { distance } \\
(\mathrm{km})\end{array}$ & $\begin{array}{c}\text { FAD } \\
\text { position } \\
\text { prediction } \\
(\mathrm{km})\end{array}$ \\
\hline 1 & 2 & 164.88 & 185.35 & 2 & 171.90 & 202.39 & 2 & 196.58 & 229.13 \\
\hline 2 & 3 & 99.42 & 126.17 & 3 & 126.50 & 151.01 & 3 & 119.22 & 147.68 \\
\hline 3 & 1 & 252.79 & 285.30 & 1 & 281.76 & 321.48 & 1 & 272.37 & 303.73 \\
\hline 4 & 3 & 185.34 & 224.26 & 3 & 183.70 & 209.88 & 3 & 159.41 & 197.44 \\
\hline 5 & 1 & 162.85 & 202.45 & 1 & 149.49 & 178.51 & 1 & 175.50 & 212.86 \\
\hline 6 & 3 & 216.70 & 256.30 & 3 & 248.97 & 261.04 & 3 & 186.79 & 224.05 \\
\hline 7 & 3 & 216.11 & 247.73 & 3 & 214.58 & 253.53 & 3 & 221.57 & 249.14 \\
\hline 8 & 3 & 136.89 & 174.06 & 3 & 109.61 & 122.58 & 3 & 130.44 & 153.30 \\
\hline 9 & 2 & 158.28 & 187.41 & 2 & 111.62 & 146.70 & 2 & 144.20 & 164.50 \\
\hline 10 & 2 & 154.08 & 188.78 & 2 & 129.18 & 150.39 & 2 & 160.50 & 189.47 \\
\hline
\end{tabular}

Table 4. Step 12 of FA Simulation

\begin{tabular}{|c|c|c|c|c|c|c|c|c|c|}
\hline \hline \multirow{3}{*}{ Vessel } & \multicolumn{3}{|c|}{ First Simulation } & \multicolumn{3}{c|}{ Second Simulation } & \multicolumn{3}{c|}{ Third Simulation } \\
\cline { 2 - 10 } & $\begin{array}{c}\text { FAD } \\
\text { destination }\end{array}$ & $\begin{array}{c}\text { FAD } \\
\text { position } \\
\text { distance } \\
(\mathrm{km})\end{array}$ & $\begin{array}{c}\text { FAD } \\
\text { position } \\
\text { prediction } \\
(\mathrm{km})\end{array}$ & $\begin{array}{c}\text { FAD } \\
\text { destination }\end{array}$ & $\begin{array}{c}\text { FAD } \\
\text { position } \\
\text { distance } \\
(\mathrm{km})\end{array}$ & $\begin{array}{c}\text { FAD } \\
\text { position } \\
\text { prediction } \\
(\mathrm{km})\end{array}$ & $\begin{array}{c}\text { FAD } \\
\text { destination }\end{array}$ & $\begin{array}{c}\text { FAD } \\
\text { position } \\
\text { distance } \\
(\mathrm{km})\end{array}$ & $\begin{array}{c}\text { FAD } \\
\text { position } \\
\text { prediction } \\
(\mathrm{km})\end{array}$ \\
\hline 1 & 2 & 90.60 & 113.56 & 2 & 83.65 & 112.47 & 2 & 151.06 & 186.71 \\
\hline 2 & 3 & 58.73 & 85.79 & 3 & 67.07 & 93.93 & 3 & 55.01 & 70.84 \\
\hline 3 & 1 & 193.81 & 209.36 & 1 & 228.28 & 257.22 & 1 & 201.56 & 232.91 \\
\hline 4 & 3 & 115.28 & 141.17 & 3 & 118.14 & 150.15 & 3 & 88.20 & 113.77 \\
\hline 5 & 1 & 102.57 & 125.79 & 1 & 91.58 & 112.76 & 1 & 112.81 & 136.81 \\
\hline 6 & 3 & 138.70 & 148.61 & 3 & 182.32 & 205.07 & 3 & 128.25 & 154.99 \\
\hline 7 & 3 & 116.02 & 141.28 & 3 & 181.79 & 189.07 & 3 & 146.60 & 170.64 \\
\hline 8 & 3 & 39.74 & 67.51 & 3 & 38.37 & 57.95 & 3 & 58.69 & 92.53 \\
\hline 9 & 2 & 73.70 & 88.15 & 2 & 54.25 & 90.04 & 2 & 69.71 & 109.63 \\
\hline 10 & 2 & 137.57 & 171.04 & 2 & 65.85 & 81.82 & 2 & 85.52 & 109.97 \\
\hline
\end{tabular}


Referring to table 3 and 4, the distance between the fishing vessels and FAD become smaller. The differences in both steps 6 and 12 are not very large, because the vessel speed cannot exceed $40 \mathrm{~km} / \mathrm{h}$, resulting in the ships still being far from the FAD. Furthermore, it can be inferred that the prediction distances from $V_{\mathrm{i}}$ to FAD differ greatly, because of the vessels' movements due to the influence of weather and sea waves. This can be seen in figure 6 , where each vessel moves to the FAD in 12 steps. FA provides a route optimization for fishing vessels toward the FAD, and enables the vessels to reach their destination quickly. Based on the simulation, we list each fishing vessel's rank to determine the most suitable objective, using equation 1 (table 5). Certain simulations were conducted with more than 12 steps, and the results indicate that most vessels are within the FAD area in steps 16 and 17. Table 5 shows the ranking of fishing vessels that obtained optimization with the minimum objective function. Generally, $\mathrm{Z}$ scores are between 0.2 and 1.01. From the first simulation conducted, $V_{10}$ is the most suitable candidate toward FAD2, followed by $V_{8}$ toward FAD3. However, this differs with other simulations, where $V_{4}$ and $V_{8}$ are the best candidates toward FAD3. From the three simulations, $V_{1}$ exhibits a constant value of the objective function.

Table 5. Rank of Fishing Vessels with FA

\begin{tabular}{|c|c|c|c|c|c|c|c|c|c|}
\hline \multirow[b]{2}{*}{ Rank } & \multicolumn{3}{|c|}{ First } & \multicolumn{3}{|c|}{ Second } & \multicolumn{3}{|c|}{ Third } \\
\hline & Vessel & Z & $\begin{array}{c}\text { FAD } \\
\text { destination }\end{array}$ & Vessel & Z & $\begin{array}{c}\text { FAD } \\
\text { destination }\end{array}$ & Vessel & $\mathrm{Z}$ & $\begin{array}{c}\text { FAD } \\
\text { destination }\end{array}$ \\
\hline 1 & 10 & 0.2142 & 2 & 4 & 0.2541 & 3 & 8 & 0.2960 & 3 \\
\hline 2 & 8 & 0.3854 & 3 & 1 & 0.3583 & 2 & 1 & 0.3337 & 2 \\
\hline 3 & 1 & 0.5827 & 2 & 2 & 0.4540 & 3 & 9 & 0.5493 & 2 \\
\hline 4 & 2 & 0.5936 & 3 & 5 & 0.5787 & 1 & 7 & 0.6328 & 3 \\
\hline 5 & 5 & 0.6275 & 1 & 9 & 0.6529 & 2 & 6 & 0.6505 & 3 \\
\hline 6 & 4 & 0.7125 & 3 & 8 & 0.6875 & 3 & 10 & 0.6681 & 2 \\
\hline 7 & 7 & 0.7463 & 3 & 3 & 0.7422 & 1 & 5 & 0.7841 & 1 \\
\hline 8 & 3 & 0.7556 & 1 & 10 & 0.7520 & 2 & 3 & 0.8060 & 1 \\
\hline 9 & 9 & 0.7953 & 2 & 6 & 0.9222 & 3 & 4 & 0.8822 & 3 \\
\hline 10 & 6 & 1.0101 & 3 & 7 & 1.0101 & 3 & 2 & 1.0101 & 3 \\
\hline
\end{tabular}

\footnotetext{
Sim $=$ simulation
}

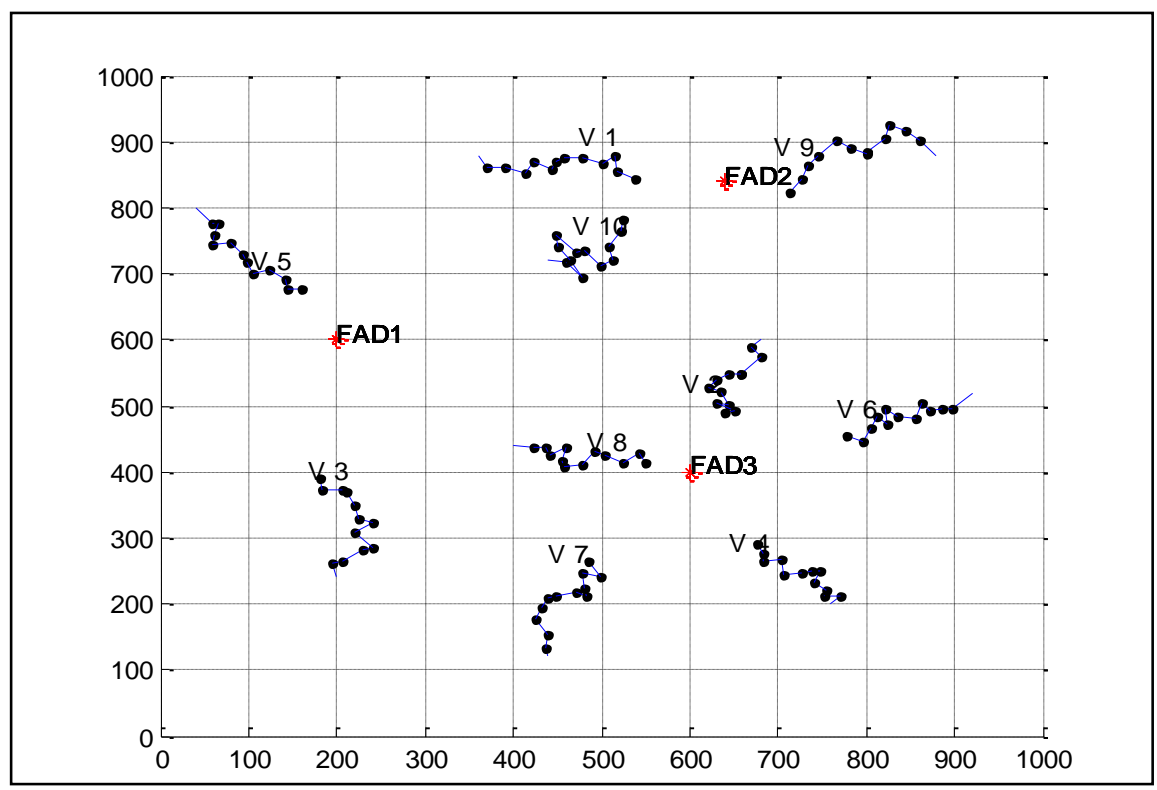

(a) First Simulation 


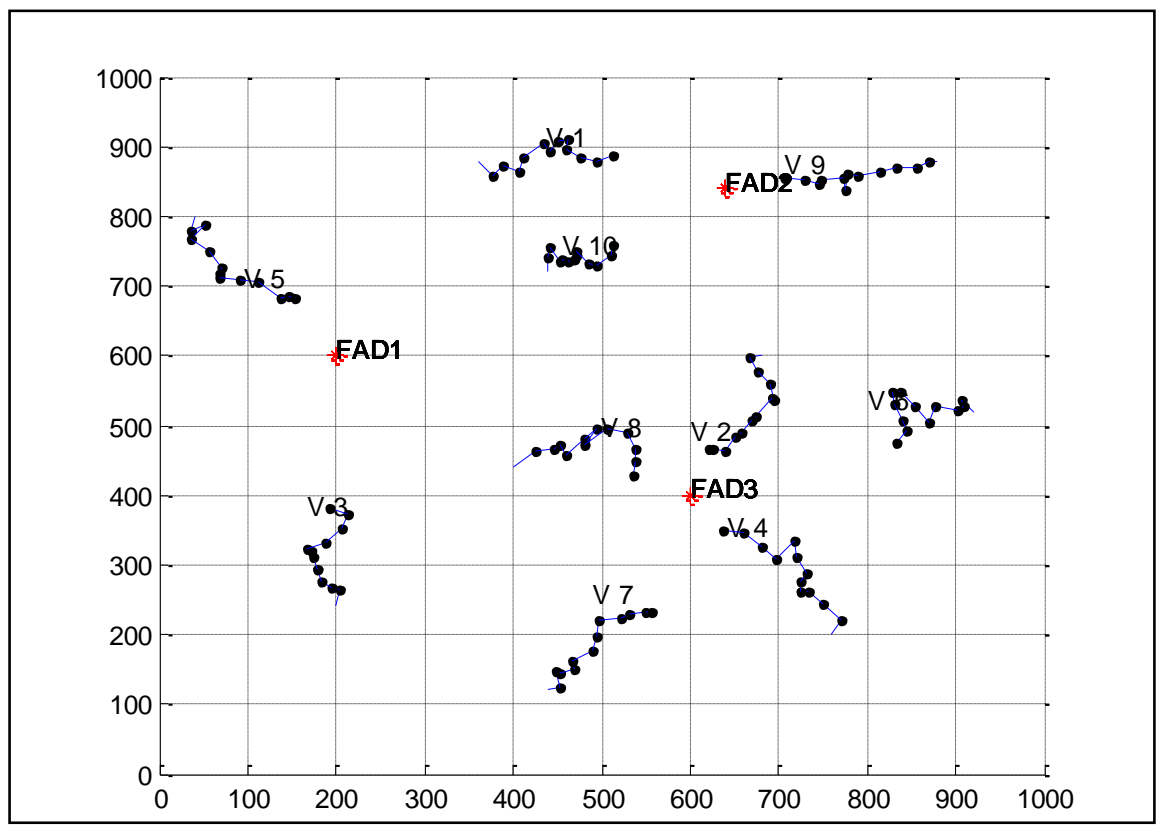

(b) Second Simulation

Figure 6. FA Fishing Vessels' Movement

GA simulation were further conducted, the results of which are shown in table 6 and 7 , which indicates that the distance between $V_{\mathrm{i}}$ and the FADs are similar with distance prediction. This is because, in GA, processes such as crossover and mutation were conducted before the next step, meaning that the best results will be used. GA requires fewer steps to reach the FAD for all $V_{\mathrm{i}}$, while FA requires many, as even in step 12, all $V_{\mathrm{i}}$ are still far from the FAD.

Table 6. Step 5 of GA Simulation

\begin{tabular}{|c|c|c|c|}
\hline Vessel & $\begin{array}{c}\text { FAD } \\
\text { destination }\end{array}$ & $\begin{array}{c}\text { FAD } \\
\text { distance } \\
(\mathrm{km})\end{array}$ & $\begin{array}{c}\text { FAD } \\
\text { prediction } \\
(\mathrm{km})\end{array}$ \\
\hline 1 & 2 & 82.843 & 82.843 \\
\hline 2 & 3 & 12.407 & 12.407 \\
\hline 3 & 1 & 160.00 & 160.00 \\
\hline 4 & 3 & 56.125 & 56.125 \\
\hline 5 & 1 & 56.125 & 56.125 \\
\hline 6 & 3 & 141.760 & 141.760 \\
\hline 7 & 3 & 122.490 & 122.490 \\
\hline 8 & 3 & 3.961 & 3.961 \\
\hline 9 & 2 & 43.411 & 43.411 \\
\hline 10 & 2 & 33.238 & 33.238 \\
\hline
\end{tabular}


Table 7. Step 9 of GA Simulation

\begin{tabular}{|c|c|c|}
\hline $\begin{array}{c}\text { FAD } \\
\text { destination }\end{array}$ & $\begin{array}{c}\text { FAD } \\
\text { distance } \\
(\mathrm{km})\end{array}$ & $\begin{array}{c}\text { FAD } \\
\text { prediction } \\
(\mathrm{km})\end{array}$ \\
\hline 2 & 2.0 & 2.0 \\
\hline 3 & 2.0 & 2.0 \\
\hline 1 & 0 & 0 \\
\hline 3 & 2.0 & 2.0 \\
\hline 1 & 2.0 & 2.0 \\
\hline 3 & 2.0 & 2.0 \\
\hline 3 & 2.0 & 2.0 \\
\hline 3 & 2.0 & 2.0 \\
\hline 2 & 2.0 & 2.0 \\
\hline 2 & 2.0 & 2.0 \\
\hline
\end{tabular}

Figure 7 illustrates the simulation of the fishing vessels' movement, which is straight toward FAD1, FAD2, FAD3, as opposed to FA. Consider the movement of fishing vessels is shown as straight line toward FAD; however, in real time the movement is not always straight toward a destination, as a result of changes in sea conditions, such as weather, sea wave height, and ocean currents.

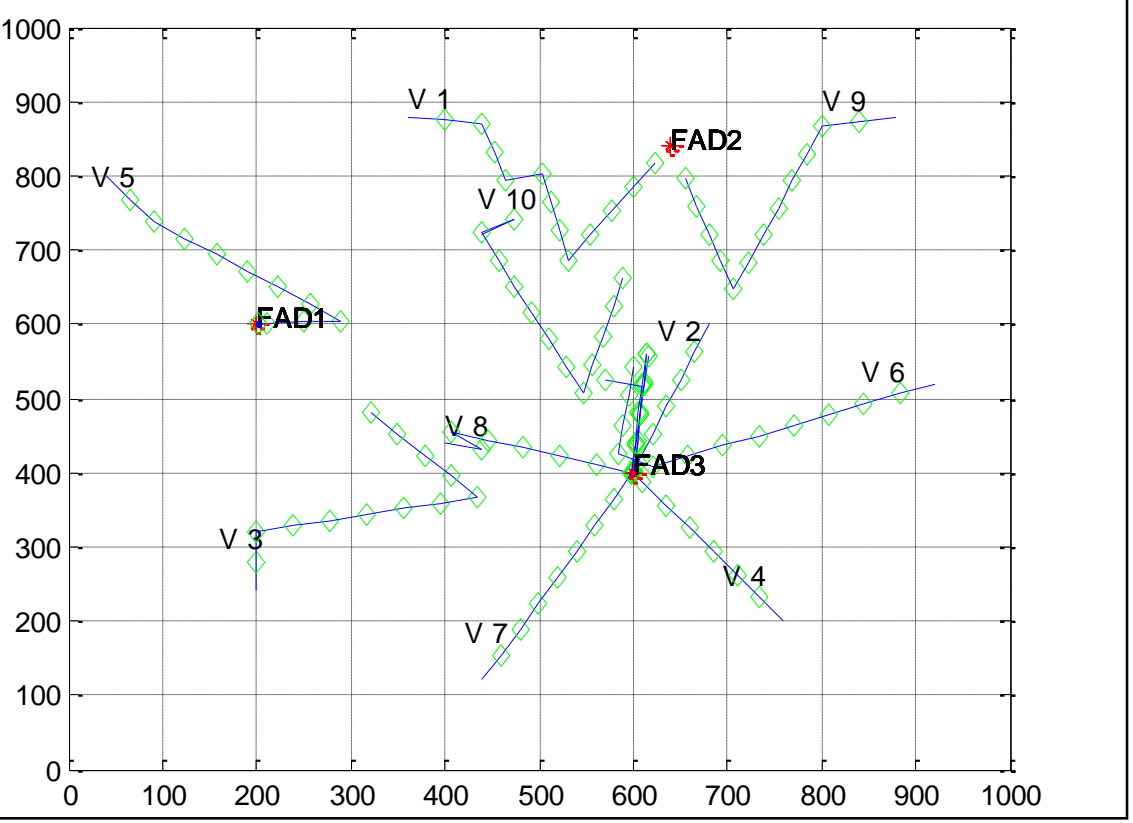

Figure 7. Modified GA Fishing Vessels' Movement

The movement of fishing vessels in the form of a straight line uses GA, because in this mechanism there is a regeneration process. The process is obtained after the crossover and mutation process, where the next generation is obtained from the best previous generation, therefore, the next distance prediction is determined from the best previous prediction. Also, consider the firefly behavior, in which equation 3 shows a rand function or random movement. The firefly behavior represented by the vessel is strongly influenced by environmental 
conditions (light/dark conditions) thus affecting the movement of the ship towards a direction that has a brighter intensity. For further exploration, this rand function should be substituted by a function that represents the movement of a real ship.

\section{Performance evaluation}

The performance of these two mechanisms can be examined from the computational complexity. The performance of the two mechanisms is shown in Table 8, where computing time complexity is performed. This result was obtained by doing iteration 24 times for each method and performed 50 times running. For GA, a new generation are raised 5 times.

Table 8. Results for time complexity after 50 runs

\begin{tabular}{|c|c|c|c|c|c|c|}
\hline \multirow{2}{*}{$\begin{array}{c}\text { Number of } \\
\text { ships }\end{array}$} & \multicolumn{3}{|c|}{ Firefly Algorithm } & \multicolumn{3}{c|}{ Genetic Algorithm } \\
\cline { 2 - 7 } & Best value (s) & $\begin{array}{c}\text { Worse } \\
\text { value (s) }\end{array}$ & $\begin{array}{c}\text { Mean } \\
\text { value (s) }\end{array}$ & $\begin{array}{c}\text { Best } \\
\text { value (s) }\end{array}$ & $\begin{array}{c}\text { Worse } \\
\text { value (s) }\end{array}$ & $\begin{array}{c}\text { Mean } \\
\text { value (s) }\end{array}$ \\
\hline 10 & 0.0650 & 0.1112 & 0.08032 & 7.445 & 14.3037 & 9.4326 \\
\hline 20 & 0.1151 & 0.2733 & 0.13852 & 15.7209 & 21.1691 & 18.49636 \\
\hline 30 & 0.2099 & 0.3225 & 0.2413 & 24.1058 & 29.3153 & 26.97218 \\
\hline
\end{tabular}

From Table 8, it can be concluded that the bigger number of vessels to choose the best $\mathrm{FAD}$, the longer the required time for both methods to perform optimization. GA takes longer than the FA.

Table 9. MAPE Scores (\%)

\begin{tabular}{|c|c|c|c|c|c|c|}
\hline \multirow{2}{*}{ Step } & \multicolumn{3}{|c|}{ FA } & \multicolumn{3}{c|}{ GA } \\
\cline { 2 - 7 } & $1^{\text {st }}$ & $2^{\text {nd }}$ & $3^{\text {rd }}$ & $1^{\text {st }}$ & $2^{\text {nd }}$ & $3^{\text {rd }}$ \\
\hline 1 & 11.46 & 11.11 & 9.93 & $9.6316 \mathrm{e}-013$ & $1.1138 \mathrm{e}-012$ & $1.0271 \mathrm{e}-012$ \\
\hline 2 & 11.85 & 12.46 & 10.59 & $8.5374 \mathrm{e}-013$ & $9.3958 \mathrm{e}-013$ & $1.2778 \mathrm{e}-012$ \\
\hline 3 & 11.92 & 11.59 & 11.54 & $2.0865 \mathrm{e}-012$ & $2.4657 \mathrm{e}-012$ & $2.0188 \mathrm{e}-012$ \\
\hline 4 & 14.40 & 13.09 & 13.64 & $3.2479 \mathrm{e}-012$ & $3.5008 \mathrm{e}-012$ & $3.7442 \mathrm{e}-012$ \\
\hline 5 & 12.89 & 15.12 & 15.35 & $1.2466 \mathrm{e}-011$ & $1.3386 \mathrm{e}-011$ & $1.2462 \mathrm{e}-011$ \\
\hline 6 & 16.34 & 14.00 & 17.17 & $3.7339 \mathrm{e}-011$ & $4.1931 \mathrm{e}-011$ & $3.3455 \mathrm{e}-011$ \\
\hline 7 & 16.70 & 15.50 & 15.42 & $7.8849 \mathrm{e}-011$ & $8.3926 \mathrm{e}-011$ & $7.5838 \mathrm{e}-011$ \\
\hline 8 & 15.18 & 16.82 & 17.68 & $7.4582 \mathrm{e}-011$ & $9.2899 \mathrm{e}-011$ & $7.3998 \mathrm{e}-011$ \\
\hline 9 & 18.20 & 17.47 & 17.71 & $7.6024 \mathrm{e}-011$ & $9.4147 \mathrm{e}-011$ & $8.7930 \mathrm{e}-011$ \\
\hline 10 & 20.05 & 22.24 & 22.03 & $7.7456 \mathrm{e}-011$ & $9.4147 \mathrm{e}-011$ & $8.7930 \mathrm{e}-011$ \\
\hline $\begin{array}{c}\text { MAPE } \\
\text { average }\end{array}$ & 16.21 & 17.29 & 16.58 & $3.64 e-011$ & $4.28456 e-011$ & $3.79681 e-011$ \\
\hline
\end{tabular}

Sim = simulation

To obtain information on the accuracy of both methods in forecasting and predicting, therefore, MAPE score is calculated. A formula of MAPE is shown in equation 4.

$$
\mathrm{MAPE}=\frac{1}{n} \sum_{i=1}^{n}\left|\frac{D_{i}-\hat{D}_{i}}{D_{i}}\right| \times 100 \%
$$

where $D_{\mathrm{i}}$ denotes the actual distance of vessel $i$ toward the FAD and $\hat{D}_{i}$ denotes the predicted distance of vessel $i$ toward the FAD. Refer to equation 4, the MAPE of FA and GA are calculated, as listed in table 9. These results are illustrated in figure 8 . Figure 8 indicates that the MAPE of GA is smaller than FA. This result proves that the accuracy of GA method is better than FA. This is because the process in the GA mechanism is complex, therefore, the predicted obtained results are more accurate. 
Both methods are an optimization process in which they display optimized and complete results with a different number of iterations, computing times, and accuracy. GA has fewer iterations to get a high accuracy, but much consume time-computing. The results of the evaluation of both methods are inferred in table 10 .

Table 10. Computational Evaluation

\begin{tabular}{|c|c|c|}
\hline Evaluation & Firefly Algorithm & Genetic Algorithm \\
\hline Time computation & Fast & Slow \\
\hline Accuracy & Fair & Excellent \\
\hline Optimal & Fair & Excellent \\
\hline Complete & Yes & Yes \\
\hline
\end{tabular}

Several similar studies have been conducted such as route optimization on GA based solar ship with the aim of maximizing the efficacy of solar energy systems and improving the energy efficiency. This research proves that the model can effectively reduce the energy waste and environmental pollution through the synergy of a sail-solar ship with route optimization [25]. Another study proposed a hybrid route-path planning model for an Autonomous Underwater Vehicle's. This model is combined two techniques, i.e. Differential Evolution and Firefly Optimization (DEFO) Algorithms. The simulation indicated that the proposed model offered an efficient performance while some assigned tasks consumed a minimum energy [26]. According to [27], an incremental transportation route algorithm is best suited to solve the route optimization problem in sea-trade than ant colony optimization (ACO) in terms of accuracy and time spent.

From previous description of similar research, there are several things that concern in a route optimization i.e. closely related to environmental and resource issues. The objective of optimization is reducing the negative impact on the environment such as air, water pollution, and resource (energy). While in this study, the impact of the route optimization is not explored, for instance, efficiency in fuel, time, or energy.

\section{Conclusion}

FA and GA provide optimization methods that can be applied to a route optimization of fishing vessels toward fishing locations. Certain parameters, such as weather, wave height, and distance to the FAD position (FAP), are major considerations in determining an efficient and profitable FAP. A route optimization using GA is more complex than FA. This is because there are several operations such as crossover and mutation, resulting in the best generation for each iteration. Based on the simulation results, FA faster computation than GA. But the accuracy of GA is better than the FA. Referring to the results of performance evaluation of both methods, it is necessary to further investigate about a movement of fishing vessel, use of fuel/energy and the impact for the environment, thus the target of optimization of the route is achieved, i.e. efficiency.

\section{References}

[1]. Q. Aini, A. Affandi, E. Setijadi, T. Terasawa, and M. H. Purnomo, "Breadth Fixed Gossip: A Route Discovery Mechanism in Ad hoc Network", International Review on Computers and Software, Vol. 11, No. 11, pp. 1028-1039, 2016.

[2]. C. V. Gopala Krishna Rao and G. Yesuratnam, "Big-Bang and Big-Crunch (BB-BC) and FireFly Optimization (FFO): Application and Comparison to Optimal Power Flow with Continuous and Discrete Control Variables", International Journal on Electrical Engineering and Informatics, Vol. 4, No. 4, pp. 575-583, 2012. 
[3]. O. Herbadji and T. Bouktir, "Optimal Power Flow Using Firefly Algorithm with Consideration of FACTS Devices UPFC", International Journal on Electrical Engineering and Informatics, Vol. 7, No. 1, pp. 12-28, 2015.

[4]. K. Guerraiche, M. Rahli, A. Zeblah, and L. Dekhici, "Series-Parallel Power System Optimization Using Firefly Algorithm", International Journal on Electrical Engineering and Informatics, Vol. 7, No. 1, pp. 89-101, 2015.

[5]. P. Leela and K. Yogitha, "Hybrid Approach for Energy Optimization in Wireless Sensor Networks", International Journal of Innovative Research in Science, Engineering and Technology, Vol. 3, No. 3, pp. 959-964, 2014.

[6]. N. C. Long, P. Meesad, and H. Unger, "A Highly Accurate Firefly Based Algorithm for Heart Disease Prediction”, Expert Systems with Applications, Vol. 42, pp. 8221-8231, 2015.

[7]. F. Mazen, R. A. AbulSeoud, and A. M. Gody, "Genetic Algorithm and Firefly Algorithm in a Hybrid Approach for Breast Cancer Diagnosis", International Journal of Computer Trends and Technology (IJCTT), Vol. 32, No. 2, pp. 62-68, 2016.

[8]. J. Kwiecien and B. Filipowicz, "Firely Algorithm in Optimization of Queueing System", Bulletin of The Polish Academy of Sciences: Technical Sciences, Vol. 60, No. 2, pp. 363368, 2012.

[9]. S. Farook and P. S. Raju, "Evolutionary Hybrid Genetic-Firefly Algorithm for Global Optimization", IJCEM International Journal of Computational Engineering \& Management, Vol. 16, No. 3, pp. 37-45, 2013.

[10]. S. Yu, S. Yang, and S. Su, "Self-Adaptive Step Firefly Algorithm", Journal of Applied Mathematics, Vol. 2013, pp. 1-8, 2013.

[11]. T. Russo, P. Carpentieri, F. Fiorentina, E. Arneri, M. Scardi, A. Cioffi, and S. Cataudella, "Modeling Landing Profiles of Fishing Vessels: An Application of Self-Organizing Maps to VMS and Logbook Data", Fisheries Research, Vol. 181, pp. 34-47, 2016.

[12]. Q. Aini, M. H. Purnomo, and A. Affandi, "Gossip algorithm approach and AODV in Vessel Messaging System: A comparison of performance", in IEEE International Conference on Control System, Computing and Engineering, Penang Malaysia, 2014, pp. 159-163.

[13]. K. Bakhrankova, K. T. Midthun, and K. T. Uggen, "Stochastic Optimization of Operational Production Planning for Fisheries", Fisheries Research, Vol. 157, pp. 147$153,2014$.

[14]. C.-H. Chen, L. P. Khoo, Y. T. Chong, and X. F. Yin, "Knowledge Discovery Using Genetic Algorithm for Maritime Situational Awareness", Expert Systems with Applications, Vol. 41, pp. 2742-2753, 2014.

[15]. E. S. Wiyono and Hufiadi, "Optimizing Purse Seine Fishing Operations in The Java Sea, Indonesia", International Journal of The Bioflux Society: Aquaculture, Aquarium, Conservation \& Legislation, Vol. 7, pp. 475-482, 2014.

[16]. G. Cosma, D. Brown, M. Archer, M. Khan, and A. G. Pockley, "A Survey on Computational Intelligence Approaches for Predictive Modeling in Prostate Cancer", Expert Systems with Applications, Vol. 70, 1-19, 2017.

[17]. S.-L. Ou, "Forecasting Agricultural Output with An Improved Grey Forecasting Model Based on The Genetic Algorithm", Computers Electronics in Agriculture, Vol. 85, pp. 33-39, 2012.

[18]. M. Satone and G. Kharate, "Feature Selection Using Genetic Algorithm for Face Recognition Based on PCA, Wavelet and SVM", International Journal on Electrical Engineering and Informatics, Vol. 7, No. 1, pp. 39-52, 2015.

[19]. R. L. Moedomo, A. S. Ahmad, A. Pancoro, J. Ibrahim, and M. S. Mardiyanto, "Simulation of Swine and Avian Influenza Viruses Recombination Based on Genetic Algorithm", International Journal on Electrical Engineering and Informatics, Vol. 2, No. 2, pp. 123136, 2010. 
[20]. Food and Agriculture Organization of the United Nations (FAO), "Fish Aggregating Device (FAD)", 2016. [Online]. Available: http://www.fao.org/fishery/equipment/fad/en. [Accessed: 10-Mar-2017].

[21]. X.-S. Yang, "Firefly Algorithms for Multimodal Optimization", in 5th International Conference on Stochastic Algorithms: Foundations and Applications, Sapporo Japan, 2009, pp. 169-178.

[22]. A. E. Hassanien and E. Emary, Swarm Intelligence: Principles, Advances, and Applications, Boca Raton, FL: CRC Press, Taylor \& Francis Group, 2016.

[23]. T. Bhatia, S. Kansal, S. Goel, and A. K. Verma, "A Genetic Algorithm Based DistanceAware Routing Protocol for Wireless Sensor Networks", Journal Computers and Electrical Engineering, Vol. 56, pp. 441-455, 2016.

[24]. BMKG - Indonesian Meteorological, Climatological, and Geophysical Agency BMKG, "Peta Prakiraan Tinggi Gelombang", 2015. [Online]. Available: http://maritim.bmkg.go.id/prakiraan/?id=b5mbPoTshPSjI3EP1MxKDqO5jAiF7GDeUS7HRYEUw0. [Accessed: 10-Nov-2016].

[25]. Y. Zhang and C. Yuan, "A Optimization Method Used for Sailing route of Solar Ship", in Proceeding of 4th International Conference on Transportation and Safety (ICTIS), Banff, Canada, 2017, pp. 541-544.

[26]. S. M. Zadeh, D. M. W. Powers, K. Sammut, and A. M. Yazdani, "Toward efficient task assignment and motion planning for large-scale underwater missions", Int. J. Adv. Robot. Syst. Vol. 13, pp. 1-13, 2016.

[27]. D. Chu, C. Li, X. Xu, and X. Zhang, "A Graph Based Framework for Route Optimization in Sea-Trade Logistics", Mathematical Problems in Engineering, Vol. 2015, pp. 1-8.

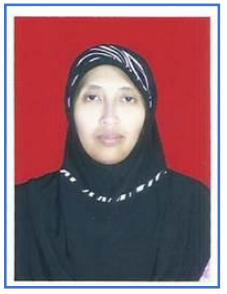

Qurrotul Aini (Corresponding Author) received her Master degree from Institut Teknologi Sepuluh Nopember Surabaya, Indonesia in 2006. Presently, she is pursuing her PhD in Telecommunication Multimedia, Department of Electrical Engineering, Institut Teknologi Sepuluh Nopember Surabaya and working as a lecturer in Department of Information System, Syarif Hidayatullah State Islamic University Jakarta. Her interest field includes Wireless Ad hoc Network, Artificial Intelligence and Multimedia Application. Email: qurrotul.aini13@mhs.ee.its.ac.id

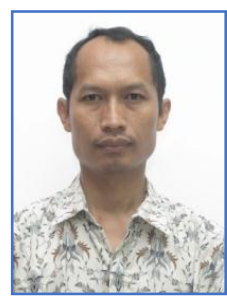

Achmad Affandi is a lecturer at Department of Electrical Engineering, Institut Teknologi Sepuluh Nopember Surabaya, Indonesia. His research interests are telecommunication network include wireless communication, elearning for rural area, and telemedicine.Email: affandi@ee.its.ac.id.

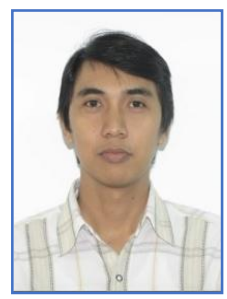

Eko Setijadi is a lecturer at Department of Electrical Engineering, Institut Teknologi Sepuluh Nopember Surabaya, Indonesia. His research interest are in telecommunication network and multimedia. Email: ekoset@ee.its.ac.id. 


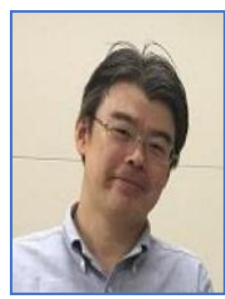

Takuya Terasawa currently is a Professor at School of Media Science, Tokyo University of Technology. His research interests are in Computer Network/Internet, IoT (Internet of Things), Machine Learning. Email: terasawa@stf.teu.ac.jp.

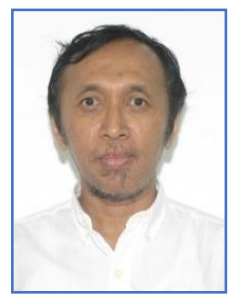

Mauridhi Hery Purnomo currently is a Professor at Department of Electrical Engineering, Institut Teknologi Sepuluh Nopember Surabaya, Indonesia. His research interests are in Artificial Intelligent Technique for Power System and Biomedical Engineering. Email: hery@ee.its.ac.id. 